\title{
Simulation Model on Movement of Goods in Sea Freight for Small and Medium Enterprise
}

\author{
Zirawani Baharum, Muhammad Hanif, Muhammad Imran Qureshi, Syazwa Nabila Mohd Raidzuan, \\ Hairulnizam Mahdin \\ Malaysian Institute of Industrial Technology, Universiti Kuala Lumpur \\ Persiaran Sinaran Ilmu, Bandar Seri Alam, 81750 Johor Bahru, Malaysia
}

\section{Article Info}

Article history:

Received Apr 11, 2018

Revised Jun 12, 2018

Accepted Jun 26, 2018

\section{Keywords:}

Business Model

Computer-Based

Development

Simulation

Witness

\begin{abstract}
Sea transportation is one of the major transportation in the scope of transport industry and plays important role towards the growth of performance in the industry that involves the movement of good (MOG). With the crucial operations, it is also essential to concern about the employee's welfare, such as long working hours that occurred due to non-systematic procedure for the MOG. The long working hours been potentitially impact to the psychological factors of works stress and physical and health effects. Therefore, this research is important to be studied in order to develop the simulation model on MOG in sea freight for small and medium-sized enterprises (SMEs), effectively and efficiency. Initially, this research is startup by defining all existed activities with the duration as required. Subsequently, the business model of MOG in sea freight is developed according to the case study in order to develop the simulation model. This research is give a guide for future research towards providing a well-computer-based by applying the decision support system, especially to manage and control the movement of goods in sea freight.
\end{abstract}

Copyright $@ 2018$ Institute of Advanced Engineering and Science. All rights reserved.

\section{Corresponding Author:}

Zirawani Baharum,

Malaysian Institute of Industrial Technology,

Universiti Kuala Lumpur,

Persiaran Sinaran Ilmu, Bandar Seri Alam, 81750 Johor Bahru, Malaysia.

Email: zirawani@unikl.edu.my

\section{INTRODUCTION}

Historically, society always located near water, partly caused by fact that water enable journey that is more efficient compared to go on land. Waterway is very important for people transport and goods throughout the world. Complex network relationship between coast port, land port, train, air, and truck route form a basis to material economic wealth throughout the world. Waterways transportation or sea transportation has been long time developed in Malaysia and it plays huge role contributing the economic growth of the country. Malaysia basically is a maritime nation. It had been estimated that the country sea area is greater than mass of earth [1].

Although in map, Malaysia's unique maritime characteristics and spreading coast outstanding. Not many national in the world can feel proud have two piece of land separated by sea with Peninsular Malaysia way separated from Sabah and Sarawak. History and progress Malaysia had deep formed by ocean around and they continue to having big influence towards socio-economic interest and strategic.

Therefore, the movement of goods and services throughout the sea is important to enterprises [2], [3], for their logistics and transportation as well, either large-scale enterprise or small medium enterprise (SMEs). Movement of goods (MOG) is the process of transferring goods from one place to another either through the rail, air, road or sea. In order to achieve urban sustainability [4], effective models such as 
computerize decision-based model for the management of urban freight movements are needed to be established [5-7].

The operation for movement of goods in sea freight is crucial in consideration of every sea operators want to keep the effectiveness of their logistics services at the optimum level. Movement of goods, operation costs, delivery speed, service quality, the management of facilities and energy saving will be improve if there is enhancement in techniques and management principles. The sea operators should always observe and update the current situation in the operation of movement of goods to provide proper operation for movement of goods in terms of management and techniques.

\subsection{Long Working Hours}

An efficient and reliable freight transportation system is one of the major factors that can create or keep positive feedback from the new customers and loyal customers as well as also increase customer satisfaction. According to the case study, employees of the company suffered on instability schedule on their daily working as well as increase their working time. In addition, the employees had to do their jobs almost ten hours and above daily and it is considered as long working hours for employees.

Delay is one of the major contributors that can give negative effect especially to the operating company. According to [8], delay in movement of goods for one day will make the company one day loss in profits. The delays in workstations affect the whole production system and lead to deviations from target throughput [9], [10]. Since the company is operating the transportation services, the delay during the services increase travel times while making working schedule not effective and flexible. Flexible scheduling means that there are interactions between the travel conditions and timing of different parts of the daily trip chain which need to be considered [11]. This is crucial which is any potential disruptions will lead the increasing of the travel time and daily working hours.

Consequences of this problem give an effect to the employees of the company. Based on Section 60A (1) Malaysia Employment Act 1955, an employee shall not be required under his contract of service to work if the employee work more than five consecutive hours without a period of leisure of not less than thirty minutes duration, more than eight hours in one day, in excess of a spread over period of ten hours in one day and more than forty-eight hours in one week. On that account, delay making the employees to work longer than expected and off from the standard working hour as stated in the Malaysia Employment Act 1955. Due to long working hours, there are few negative impacts that the employees will be suffered on their life.

\subsection{Impact of Long Working Hours on Psychological Factors and Work}

Long working hours negative impact to the psychological and health of the workers. Psychological factor means in terms of work stress and work-family conflict. Work-family conflict is a type of certain conflict between where stress from work role that incompatible with pressure from family role. Indeed, generally the degrees of both work stress and work-family conflict increase gradually from no overtime work to overtime work [12]. The book also states that work-family conflict is the highest among salaried workers with mandatory overtime work.

According to [13] on Malaysian Digest, careers interfere the relationship is one of main causes contribute to the $35.3 \%$ divorce cases in the country. She also state that working longer hours will give negative effect to the couple's relationship and marriage. Instead of concerning those two types of human relationship, the other parties also will suffer from long working hours which is the children. Children unfortunately can be victim on job stress from their parents such as child abuse.

The terms of child abuse can be used for neglect of children and maltreatment. Child maltreatment means all forms of physical and/or emotional ill-treatment, sexual abuse, neglect or negligent treatment or commercial or other exploitation, resulting in actual or potential harm to the child's health, survival, development or dignity in the context of a relationship of responsibility, trust or power [14]. Victims of abuse can experience depression and humble, two terms that would encourage behavior that is risky. Meanwhile, the probability to have injected illegal drugs was more likely five times to those people who were abused as children [15].

\subsection{Impact of Long Working Hours on Physical and Health Effects}

Health is the most important that people need to care about in life which also one of the most crucial thing perform great performance in working career. In terms of working career, sadly to mention people who working long hours will affect to their health.

A new study of more than 600,000 individuals in Australia, United States of America, and Europe, broadcasted in the [16] a medical journal stationed in United Kingdom, find that people who more than 55 hours a week or more have risk 33\% larger stroke and risk 13\% greater than coronary heart disease. Despite, the excessing working hour also could give an effect to their physical and health. Type 2 diabetes, 
characterized by hyperglycemia and insulin resistance or insulin insufficiency, causes substantial disease burden [17]. Working long hours is also associated with an increased risk of cardiovascular disease, which is one of the complications of type 2 diabetes [18], [19].

In this research had mentioned that the employees of real case study suffered from long working hours which exceeding eight hours per day. In other than that, this working life incurred by employees could possibly get dangerous disease and it is endangering their life.

\section{RESEARCH METHOD}

The current study used a qualitative research design using interview approach to collect data from the respondents. Accurate and systematic data collection is critical to conducting educational research. Before proceed with the data collection researcher doing the critical literature review in getting the varibales and for the problem identification. Data collection allows to collect the information that desired to collect regarding to the topic of the research. For example, data collection on this research is to develop the simulation model on movement of goods in sea freight for small and medium-sized enterprises (SMEs). Depending on the study type, methods of the data collection including document review, observation, questionnaire, measuring or combination of different methods. Similar to this research, the instruments of the data collection will be via interview session with the employees of the real industry.

In order to get as much as possible the data that is convenient, instruments like interview and literature review is executes in direction of continuing to the next phases. The advantages of this successful and proper data collection include ability to answer research question accurately, identify and confirming issues as well as theories. Another advantage of the data collection is can help to deal by proactive issue, measure progress and make full use of the opportunity. Collecting data can help measure condition of affairs, unlimited to case or particular occasion. When data grouped, detected and analysed with way that is reliable from time to time, it becomes may be to measure progress and success. Following that, interview as one of the instruments in this research will be done. The interview will involve the employees of the real industry. The inputs from the respondents of the interview will provide additional information and data on the part of accomplish goal.

On the other hand, face to face interview will be use as interview method in this research. Face to face interview is data gathering method when interviewer continues to communicate with respondent according to questionnaire prepared. This method enables to obtain factual information and other information that out during conversation with respondent. Therefore, face to face interview method ensures data quality will be achieved and increase response rate.

In brief, data collection will give huge impact to the successful together with contributing to continue next phases, the simulation model development. By conducting interview as instrument in this section, it will help to collect the fresh, new and primary information with greater understanding in conjunction with increasing the knowledge of the researcher where new ideas might come up after the interview session with the respondent.

Meanwhile, it is also give benefit for the respondent as he allows describing what is important to him and other workers depending on the topic discussed. For example in this research, an operation manager as the respondent during the interview might be describe what he want in order to solve the problem that they are facing or suggest recommendations for the topic of this research. Every conversation between the researcher and respondent is organised and analysed by transcription and coding analysis.

The simulation model development is a process where the imitation operation of real-world process or system. To simulate the operation as real-world, the simulation model require to develop by understand the key of theor charecteristics, behaviours and functions. One of the popular technique used is by represents the MOG in sea freight operation using an algorithm such as flowchart in order to show the logic of the system proposed or model development. The simulating process has be executed to verify and validate the representation of the real-world model into the simulation model. As many as software for simulation, researcher has choose the WITNESS software package as the tool to examine the simulate process. The flow of the research method is presents in Figure 1. 


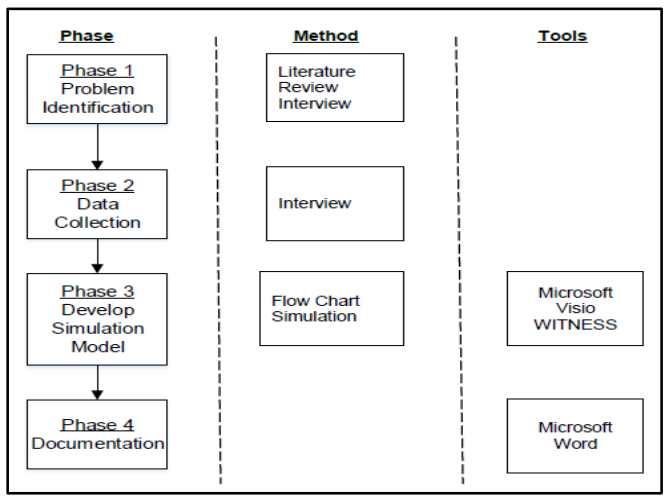

Figure 1. The research methodology

\section{RESULT AND DISCUSSION}

\subsection{Qualitatitive Data}

Interview method is using by the researcher in order to find additional information related to this research. The employee at real case study is selected as the respondent for interview session. The researcher uses this method as to find actual evidence or data as required. For this process, every information or data collected from the selected method will be gathered to answer the research questions. The data from literature review and interview are supporting in this process. This is the first data need to collect through the interview session. This data is important as the researcher need to have knowledge regarding to overall process of movement of goods practiced by the chosen company.

Therefore, the researcher need to identify how much time was took to complete overall process of movement of goods applied by the company. In this section, the researcher also wants to validate whether the issue of the research is occur at the chosen company workplace. The questions and responses had been showed in the Table 1.

Table 1. Questions and Responses on Movement of Goods Operations

\begin{tabular}{lll}
\hline No & Questions & Responses \\
\hline $1 \quad \begin{array}{l}\text { Can you explain sir how the movement of } \\
\text { goods operations implemented by your } \\
\text { company? }\end{array}$ & $\begin{array}{l}\text { First of all, our company implementing shipping service similar to other } \\
\text { companies in the same industry. We have followed the general process } \\
\text { of Standard of Procedure (SOP) and also referring to Malaysian Marine } \\
\text { Department and Royal Malaysian Customs Department (RMCD). } \\
\text { The whole transportation process takes about } 11 \text { hours. }\end{array}$ \\
$\begin{array}{l}\text { That was good action taken by your company, } \\
\text { sir. But, can I know how much time taken for }\end{array}$ & $\begin{array}{l}\text { Tour company to complete whole } \\
\text { transportation process? }\end{array}$ \\
$\begin{array}{l}\text { In terms of loading and unloading process, } \\
\text { how much it take to complete, sir? }\end{array}$ & $\begin{array}{l}\text { The process of loading goods from point of origin which is our base } \\
\text { jetty at Pulau Kambing took } 2 \text { hours and } 30 \text { minutes. It is same goes } \\
\text { when we unloading goods at the point of destination which is at Redang }\end{array}$ \\
$\begin{array}{ll}\text { And how much it takes for one roundtrip to } \\
\text { Redang Island, sir? }\end{array}$ & $\begin{array}{l}\text { Island jetty. } \\
\text { The whole journey took } 6 \text { hours. It is the fixed time if the weather and } \\
\text { surf conditions in a good state. Unfortunately, we have to slow down } \\
\text { our ship if there is strong winds and rough seas during the journey as } \\
\text { well as we have to suffer a great time to reach the destination. }\end{array}$ \\
&
\end{tabular}

According to the response from the respondent in this question, the operations or process of movement of goods practiced by case study company have follow standard or general process movement of goods in shipping industry. The respondent also state that his company following rules and regulations from Malaysian Marine Department and Royal Malaysian Customs Department (RMD) regarding requirements on transporting goods by sea. It means that this company is well aware about the law of sea transportation.

Concerning about the duration of all activities on movement goods, the respondent has said that all delivery process took 11 hours. This is where the issue in this research arise which is the workers of chosen company had facing long working hours at their workplace. According to the response, it is wise to say that the schedule time of the workers is off from the standard hour. As been described before from the previous chapter, it is not permissible for the worker to work more than eight hours in one day, in excess of a spread 
over period of ten hours in one day and more than forty-eight hours in one week under Section 60A (1) Malaysia Employment Act 1955.

Main objective of this research is to define all current activities with the duration of movement of goods in sea freight for SME. Regarding to the process of movement of goods practiced by the chosen company, it is the complete activities from point of origin to the point of destination together with duration of main process. Details list of activities on movement of goods practiced by this case study is show in the Table 2. From qualitative method of interview, 13 activities is identified from 4 main processes in order to develop the business model.

Table 2. List of Movement of Goods Activity with Duration

\begin{tabular}{|c|c|c|c|}
\hline Process & $\begin{array}{l}\text { Activity } \\
\text { Coding }\end{array}$ & Activity & Duration (Minutes) \\
\hline \multirow{5}{*}{$\begin{array}{l}\text { Loading } \\
\text { Process }\end{array}$} & Loading1 & Waiting for arrival of suppliers' truck & 2 hours 30 minutes \\
\hline & Loading2 & Check bill of loading & \\
\hline & Loading3 & Unloading goods from truck & \\
\hline & Loading4 & Loading goods into ship & \\
\hline & Loading5 & Final checking of goods & \\
\hline \multirow{2}{*}{$\begin{array}{l}\text { Depart to } \\
\text { Redang Island }\end{array}$} & Depart1 & Arrival at Redang Island jetty & 3 hours \\
\hline & Depart2 & Docking at Redang Island jetty & \\
\hline \multirow{4}{*}{$\begin{array}{l}\text { Unloading } \\
\text { process }\end{array}$} & Unloading1 & Bill of Loading process & 2 hours 30 minutes \\
\hline & Unloading2 & Unloading goods from ship & \\
\hline & Unloading 3 & Loading goods into truck & \\
\hline & Unloading4 & Final checking on goods & \\
\hline Embark & Embark1 & Arrive at Pulau Kambing jetty & 3 hours \\
\hline Pulau Kambing & Embark2 & $\begin{array}{c}\text { Anchor at Pulau Kambing jetty } \\
\text { Total }\end{array}$ & 11 hours \\
\hline
\end{tabular}

\subsection{Business Model}

Consequently, after all the qualitative data is obtained and transcript, the business model of movement of goods in sea freight for SME is been developed. It is developed using the flowcharting technique. A flowchart is a diagram defining an algorithm, workflow or process, showing the steps as boxes of numerous types, and their order by connecting them with arrows. The flow chart used in analyzing, designing, documenting or managing a process or program in various fields. The business model of the movement of goods activities in sea freight applied by this case study company is shown in Figure 2. This diagram illustrates a representative the simulation model of a solution to a given problem.

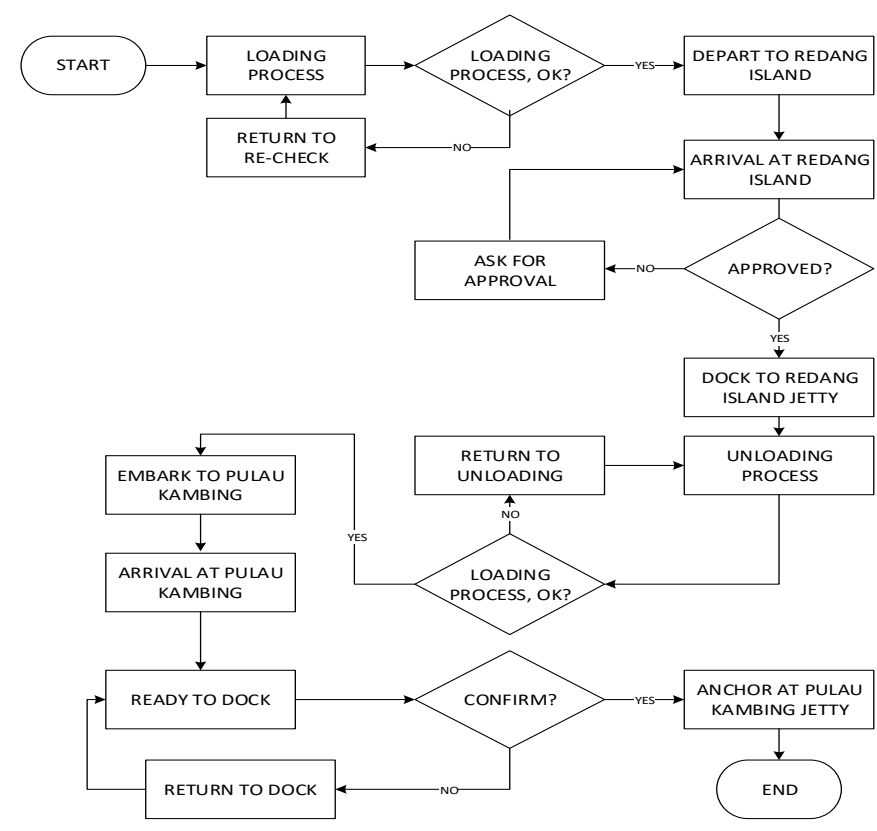

Figure 2. Business model on movement of goods in sea freight for simulation 
The main process is representing as what is general flow that happened in the chosen company during delivery service. The 4 main process are loading process, depart to Redang Island, unloading process and embark to Pulau Kambing. While, there are all inclusive 13 activies extracted from the 4 main processes, which are waiting for arrival of suppliers' truck, check bill of loading, unloading goods from truck, loading goods into ship, final checking of goods, arrival at Redang Island Jetty, docking at Redang Island jetty, bill of loading process, unloading goods from ship, loading goods into truck, final checking on goods, arrive at Pulau Kambing jetty and anchor at Pulau Kambing jetty.

\subsection{Simulation Model Development}

From the findings, researcher developed model that can be utilized to minimize the delay in loading or unloading process that can reduce working hours of the workers and can save them from harmful effect of the long working hours. The delay process could be also minimize from the simulation model development due to proper managing their process when something unpreditable event occur. This simulation model can be proposed to establish an auto-computerized and decision-based model for MOG in sea freigth as most researchers suggest in their investigation [20], [21]. The last step of this research is the development of simulation model on movement of goods in sea freight for SMEs.

The tools that the researcher uses to do simulation model is by using WITNESS Manufacturing Simulation software. This software will show how the process of movement of goods activity converted into simulation. In addition, WITNESS Manufacturing Simulation software have been used to make simulation as to help the researcher in proposing new method to the chosen company to make decision making towards its movement of goods operations in the future. The chosen company can use this method if they need to reconstruct their existing process. More than that, the chosen company also can see if there is any flaw in the operations more clearly by using this simulation.

In developing the simulation model, the researcher needs to undergo several steps. It is important to have the knowledge about what are the elements that suitable to use in developing simulation model for this research. Designer Elements are user-defined palette to display and detailed parameters that have been determined. The function of Designer Elements is to produce the basic elements that contain in the model. The box of Designer Elements is show in Figure 3.

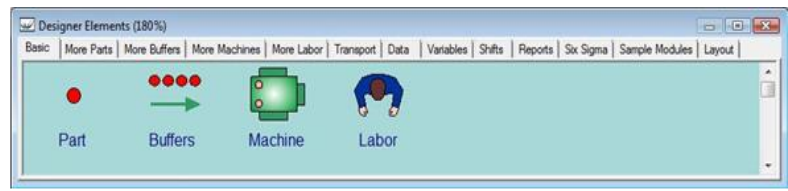

Figure 3. The designer elements

Designer Elements window has many tabs with categorized elements of the designer. It is used to accelerate the construction of the model. Each element of the design can be modified by the user and stored either with models or separately which is to file a designer of elements. Designer Elements can be added or deleted. A new tab can be added to the Designer Elements windows and occupies with new design elements. In this study, the researcher has uses several number of basic elements in the Designer Elements windows when developing the simulation model. The list of basic elements is show in the Table 3 .

The process of selection of designer elements will move to the next process which designing simulation model. All the selected elements which require in developing simulation model for this research will be arranged coordinately referring from the flow chart. Designing the simulation model is important to validate whether it is logic or not for the process. In fact, the selection of designer elements and the arrangement of elements are very crucial to ensure the logical of the process. Those selected elements should support with the function of the process that need to simulate.

After the arrangement of basic elements complete, the simulation model will move to the next step which is pull and push method. Push method in the WITNESS refers to entities or vehicles are sent to the next available element in a preferred order list which is capable of accepting them. For example, parts serve as goods push to the first process which is loading process. Meanwhile, pull method refers to entities are taken from the available element in a preferred order list which is capable of supplying them. For example, loading process pull from goods. After this step is complete, the simulation model can be run. After the arrangement of the selected elements complete according to the flow chart of business model applied by Berkat Usaha Diesel Sdn Bhd, The complete simulation model will show in the $2 \mathrm{~d}$ and $3 \mathrm{~d}$ types as look in the Figure 4, Figure 5 and Figure 6. 


\begin{tabular}{ll}
\multicolumn{1}{c}{ Table 3. List of Basic Elements } \\
\hline Elements & Description \\
\hline Parts & $\begin{array}{l}\text { Parts are used to represent their discrete goods moving around } \\
\text { model. In this study, part is serve as goods which need to transport } \\
\text { Icon }\end{array}$ \\
Path & This element is serve as physical route of the ship journey in the \\
model & This is main element which normally used to take part from \\
somewhere and send them to the next destination. In this study, this \\
element represent as process in the operations \\
Conveyor \\
The function of this element is to move parts from one fixed points \\
in the model. In this study, conveyor is used to show the flow of the \\
process \\
The function of this element represents as vessels used in the process \\
in the model \\
This element is used to represent loading and unloading process \\
Work Cell
\end{tabular}

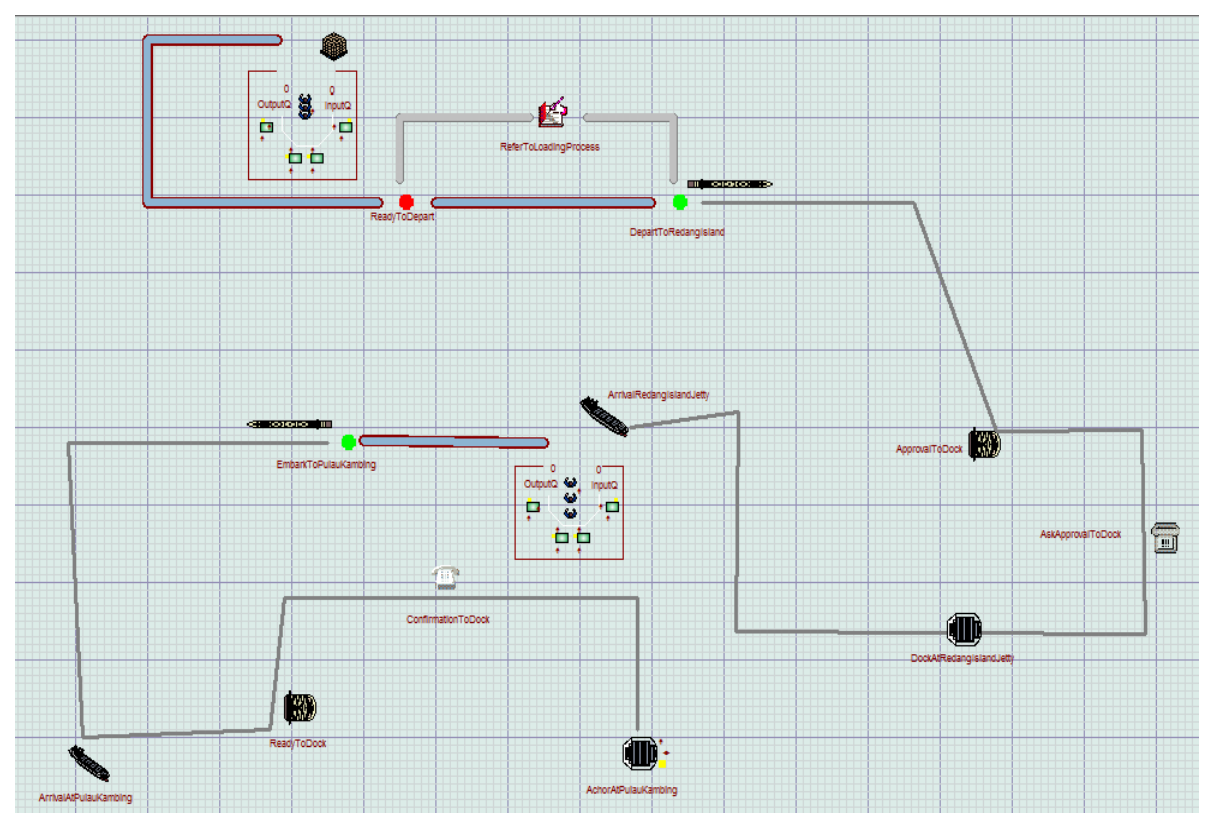

Figure 4. Simulation model in 2D

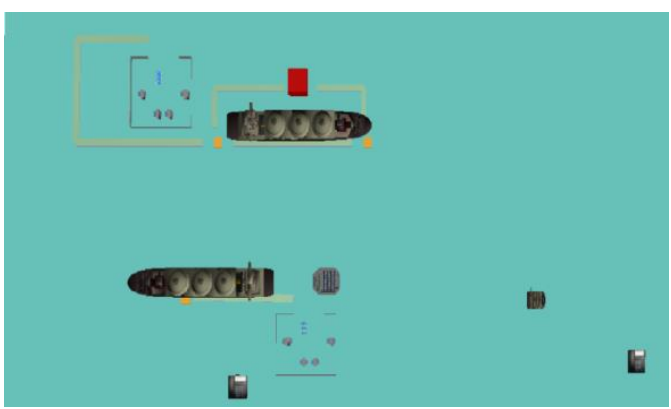

Figure 5. Simulation model in 3D from above view 


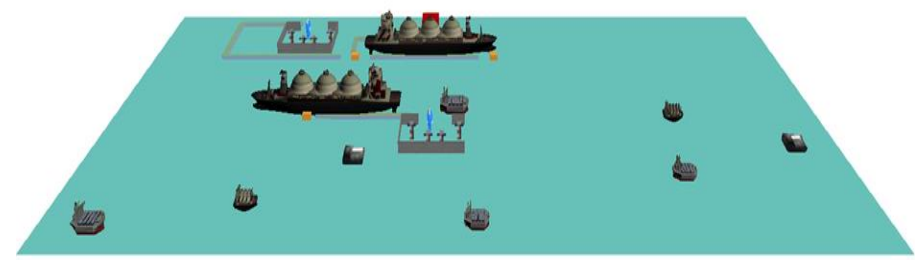

Figure 6. Simulation model in 3D from side view

\section{CONCLUSION}

As a growth development in sea freight industry, the movement of goods becomes a crucial element for the businesses. By developing the computerized-based solution fot this type of business lead this industry to be more efficient and effective. Inconsistent activities while managing the movement of good leads to long working hours issues among the workers that creates the psychological factors of works stress and physical and health effects.

As a solution to circumvent the matters, an interview session has been conducted in order to list out all the processes and activities for business model development. Hence, the simulation model on movement of goods in sea freight is developed as referred through the business model of the case study. The interview is conducted using the qualitative approach, while the business model is developed by flowcharting technique and generated via Microsoft Visio. The simulation model is developed using the WITNESS simulation software that begins with designing the basic element by Designer Element. The simulation model is shown in Chapter 3.3 in 2D model and 3D model of view. The simulation model is developed to show the movement of every process in simulation view by using WITNESS. Any analysis on this movement of goods process by using this software has been recommended for future research. The information have been gathered will be the guideline to the researcher to recommend the best solution to overcome the problem statement in this research.

\section{REFERENCES}

[1] T. Neville Postlethwaite, R. Murray Thomas. Schooling in the ASEAN Region: Primary and Secondary Education in Indonesia, Malaysia, the Philippines, Singapore, and Thailand. Oxford. Pergamon Press. 2014.

[2] Lee T. C. Economy-wide Impact Analysis of a Carbon Tax on International Container Shipping. Transportation Research Part A: Policy and Practice, 2013; 87-102.

[3] Stajniak M. The Impact of Transport Processes Standardization on Supply Chain Efficiency. LogForum, 2016; 37 46.

[4] Maria Lindholm, Sonke Behrends. Challenges in Urban Freight Transport Planning - A Review in The Baltic Sea Region. Journal of Transport Geography. 2012. 22: 129-136.

[5] Valerio Gatta, Edoardo Marcucci. Urban Freight Transport and Policy Changes: Improving Decision Makers' Awareness via an Agent-Specific Approach. Transport Policy. 2014. 36: 248-252.

[6] Angel Ibeasa, Jose L. Mouraa, Agostino Nuzzolob, Antonio Comi. Urban Freight Transport Demand: Transferability of Survey Results Analysis and Models. Procedia - Social and Behavioral Sciences. 2012. 54(2012): 1068-1079.

[7] Edoardo Marcucci, Michela Le, Pira, Valerio Gatta, Giuseppe Inturri, Matteo Ignaccolo, Alessandro Pluchin. Simulating Participatory Urban Freight Transport Policy-Making: Accounting for Heterogeneous Stakeholders' Preferences and Interaction Effects. Transportation Research Part E: Logistics and Transportation Review. 2017. 103: 69-86.

[8] Pilime S. Delay Affecting Export Earnings. Business Reporter. Lupen State University. 2016.

[9] Ozkok E. S. Modelling Critical Illness Claim Diagnosis Rates 1: Methodology. Scandinavian Actuarial Journal. 2014; 5: 439-457.

[10] Ozkok E., Streftaris G., Waters H.R., Wilkie A.D. Bayesian Modelling of The Time Delay Between Diagnosis and Settlement for Critical Illness Insurance using a Burr Generalised-Linear-Type Model. Insurance, Mathematics and Economics. 2012. 50: 266-279.

[11] Jenelius E.The Value of Travel Time Variability with Trip Chains, Flexible Scheduling and Correlated Travel Times.Transportation Research Part B: Methodological. 2012. 46(6): 762-780.

[12] Terry A. Beehr. Psychological Stress in the Workplace (Psychology Revivals). New York. Routledge. 2014.

[13] Lakshiny. Divorce Statistics Show That Work Is Getting In The Way Of Marriage - Here's How You Can Save Yours Before It's Too Late. Malaysia Digest. 2016.

[14] John Eckenrode, Elliott G. Smith, Margaret E. McCarthy, Michael Dineen. Income Inequality and Child Maltreatment in the United States. American Academy of Pediatrics. 2014. 133(3): 454-461.

[15] Chris Woolston. Workplace Habits: Full-Time is Full Enough. Nature. 2017. 546: 175-177. 
[16] Kivimäki M., M. Jokela, Solja T. N., Archana S. M., Eleonor I. F., Lars A., Jakob B. B., Marianne B., Herman B., Annalisa C., Els C. Long Working Hours and Risk of Coronary Heart Disease and Stroke: A Systematic Review and Meta-Analysis of Published and Unpublished Data for 603838 Individuals. The Lancet. 2015. 386: 1739 1746.

[17] Yang G., Yu W., Yixin Z., George F. G., Xiongfeng L., Maigeng Z., Xia W., Shicheng W. Rapid Health Transition in China, 1990-2010: Findings from The Global Burden of Disease Study 2010. The Lancet. 2013. 381:9882. 1987.

[18] Virtanen M., Heikkila K., Jokeia M., Ferrie J. E., Batty G. D., Vahtera J., Kivimaki M. Long Working Hours and Coronary Heart Disease: A Systematic Review and Meta-Analysis. American Journal of Epidemiology. 2012. 176(7): 589-596.

[19] Toivanen, S. G., Rosane H. G., Christin M., Stig V., Sandra E. Mortality Differences between Self-Employed and Paid Employees: A 5-Year Follow-Up Study of The Working Population in Sweden. Occupational and Environmental Medicine. 2016. 73(9): 627-636.

[20] G. Venille. Simulation Analysis for Consistent Path Identification to Refine the Network Lifetime. Indonesian Journal of Electrical Engineering and Computer Science. 2017. 8(3): 674-678.

[21] EYazao Yang, Hailin Si, Xiaoni Hao, Junshao Luo. Traffic Impact Simulation for Road Construction Project. TELKOMNIKA. 2012. 10(8): 2176-2182. 